\title{
Cystic fibrosis transmembrane conductance regulator modulators in cystic fibrosis: current perspectives
}

\author{
This article was published in the following Dove Press journal: \\ Clinical Pharmacology:Advances and Applications \\ 21 September 2016 \\ Number of times this article has been viewed
}

\author{
Béla Z Schmidt ${ }^{1}$ \\ Jérémy $B$ Haaf ${ }^{2}$ \\ Teresinha Leal ${ }^{2}$ \\ Sabrina Noel ${ }^{2}$ \\ 'Stem Cell Biology and Embryology, \\ Department of Development and \\ Regeneration, Katholieke Universiteit \\ Leuven, Leuven, ${ }^{2}$ Louvain Center for \\ Toxicology and Applied Pharmacology, \\ Université Catholique de Louvain, \\ Brussels, Belgium
}

\begin{abstract}
Mutations of the CFTR gene cause cystic fibrosis (CF), the most common recessive monogenic disease worldwide. These mutations alter the synthesis, processing, function, or half-life of CFTR, the main chloride channel expressed in the apical membrane of epithelial cells in the airway, intestine, pancreas, and reproductive tract. Lung disease is the most critical manifestation of CF. It is characterized by airway obstruction, infection, and inflammation that lead to fatal tissue destruction. In spite of great advances in early and multidisciplinary medical care, and in our understanding of the pathophysiology, $\mathrm{CF}$ is still considerably reducing the life expectancy of patients. This review highlights the current development in pharmacological modulators of CFTR, which aim at rescuing the expression and/or function of mutated CFTR. While only Kalydeco ${ }^{\circledR}$ and Orkambi ${ }^{\circledR}$ are currently available to patients, many other families of CFTR modulators are undergoing preclinical and clinical investigations. Drug repositioning and personalized medicine are particularly detailed in this review as they represent the most promising strategies for restoring CFTR function in CF.
\end{abstract}

Keywords: high-throughput screening, drug repositioning, personalized medicine, precision medicine, potentiators, correctors

\section{Introduction}

\section{Cystic fibrosis and the CFTR gene}

Cystic fibrosis (CF) is an inherited (recessive autosomal) chronic disease that affects the respiratory, digestive, and reproductive systems. Although intestinal symptoms are usually the first to occur during the life of the patient, it is the progressive lung damage, due to cycles of infection/inflammation, that finally leads to irreversible lung disease and death. With $\sim 90,000$ people diagnosed, a prevalence of 1/2,500 and about one carrier among 25 individuals, $\mathrm{CF}$ is the most common life-threatening Mendelian disorder worldwide. Advances in research and medical treatments have raised the life expectancy of CF newborns beyond 50 years; however, the current median age of survival for CF patients is still in the late 20s.

$\mathrm{CF}$ is caused by mutations in the $\mathrm{CF}$ transmembrane conductance regulator $(C F T R)$ gene, which was cloned and identified as the gene affected in CF in $1989 .{ }^{1}$ CFTR gene encodes the main anion channel expressed in the epithelium. Additionally, CFTR is also expressed in many other cells types (eg, fibroblasts, ${ }^{2}$ neurons, ${ }^{3}$ cardiomyocytes, ${ }^{4}$
Correspondence: Sabrina Noel Louvain Center for Toxicology and Applied Pharmacology, Université Catholique de Louvain, Avenue Mounie 53, BI.52.12, BI200 Brussels, Belgium $\mathrm{Tel}+3227649471$

Fax +3227645336

Email sabrina.noel@uclouvain.be 
and immune cells $\mathrm{s}^{5-7}$ ), where its function is not always well known. Among the 2,000+ CFTR mutations identified so far (http://genet.sickkids.on.ca), only a fraction of them causes CF. These CF-causing mutations induce a decrease or a loss of function of CFTR at the plasma membrane. In the lung, the lack of CFTR leads to dehydration of the airway surface liquid and drives the cascade of pathological events characteristic of CF (Figure 1).

\section{Structure of CFTR}

The CFTR gene contains 27 exons spanning $250 \mathrm{~kb}$ on the long arm of chromosome 7 (7q31.2). ${ }^{8,9}$ The encoded mRNA is $\sim 6.5 \mathrm{~kb}$ long and is translated into a protein of 1,480 amino acids. The CFTR protein belongs to the adenosine triphosphate (ATP)-binding cassette (ABC) transporters and functions as an adenosine $3^{\prime}, 5^{\prime}$-cyclic monophosphate (cAMP)-regulated chloride channel in a variety of polarized epithelial cells. ${ }^{10}$ The predicted protein structure is shown in Figure 2.

The $\mathrm{R}$ domain is a unique structural feature of CFTR as it is not found in other ABC transporters. ${ }^{11}$ The $\mathrm{R}$ domain is highly charged and contains multiple consensus sequences for protein kinase A phosphorylation ${ }^{12,13}$ as well as target sites for other kinases. ${ }^{14-16}$ Phosphorylation of the $\mathrm{R}$ domain of CFTR is necessary for channel activity: when unphosphorylated, the R domain inhibits CFTR. ${ }^{17,18}$ Although the phosphorylation of the $\mathrm{R}$ region is required, it is not sufficient for opening the CFTR channel ${ }^{13,19-21}$ nor for the interaction with multiple binding partners. ${ }^{22,23}$ Moreover, phosphorylation of the $\mathrm{R}$ domain also regulates the membrane stability of CFTR by modulating the balance between endocytosis and exocytosis. ${ }^{24}$

ATP binding and hydrolysis by the nucleotide-binding domains (NBDs) is a prerequisite to anion transport through CFTR channels. ${ }^{25,26}$ The two NBDs form a head-to-tail dimer

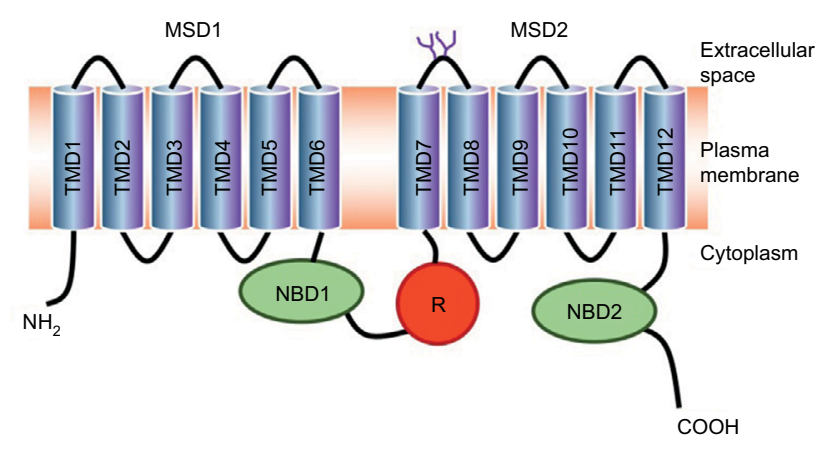

Figure 2 Predicted topology of CFTR protein.

Notes: It is composed of two repeated units made of a MSD followed by a NBD. The two repeated units are linked by a R domain. The MSDs consist of six hydrophobic transmembrane helices (or TMD). Several transmembrane helices contain one or more charged amino acids that control anion permeability. Extracellular loop 4 (between TMD7 and TMD8) contains two N-glycosylation sites.

Abbreviations: CFTR, cystic fibrosis transmembrane conductance regulator; MSD, membrane-spanning domain; NBD, nucleotide-binding domain; TMD: transmembrane domain; $\mathrm{R}$, regulatory domain.

\section{Gene replacement - gene editing mRNA repair-based therapy}

CFTR modulators

ENaC inhibitors Alternative chloride channel activators Hypertonic saline Hyperosmotic agents

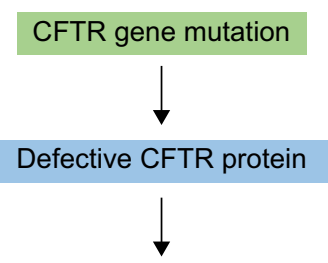

Abnormal epithelial ion transport Airway surface liquid depletion Defection mucociliary clearance

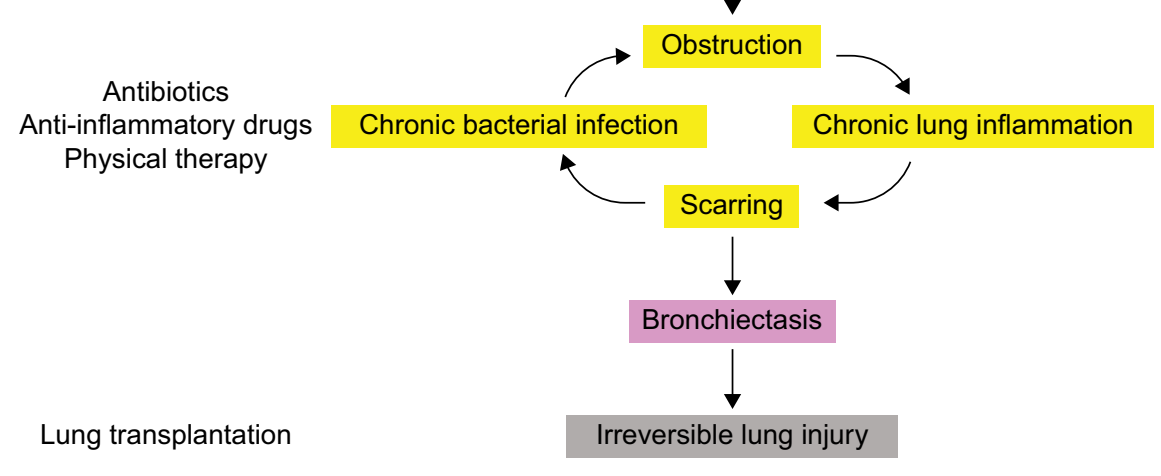

Figure I Pathophysiology of CF lung disease and potential therapies targeting the basic defect or the symptoms.

Note: In the absence of conclusive data on gene therapy, CFTR modulators are the most proximal therapy for CF currently in development.

Abbreviations: CF, cystic fibrosis; CFTR, cystic fibrosis transmembrane conductance regulator; ENaC, epithelial sodium channel; mRNA, messenger RNA. 
with two ATP-binding sites located at the dimer interface. ${ }^{27}$ Within this dimer, ATP binds to NBD1 but is hydrolyzed at the NBD2 ATP-binding site. ${ }^{27-29}$ ATP interaction with NBDs facilitates their dimerization and induces conformational changes in the membrane-spanning domains required for the gating of CFTR channel. ${ }^{26}$

\section{CFTR function(s): not only a chloride channel}

CFTR is the only ABC transporter functioning as an ion channel. The characteristic properties of CFTR-associated conductance are a linear current-voltage relationship and a single conductance of $6-11 \mathrm{pS} .{ }^{30,31}$ Although CFTR may also transport negatively charged organic molecules such as gluconate ${ }^{32}$ and glutathione, ${ }^{33,34}$ it is mostly selective for monovalent anion. In vivo, it mainly transports $\mathrm{Cl}^{-}$and $\mathrm{HCO}_{3}^{-} \cdot 31,35$ Lack of apical $\mathrm{Cl}^{-}$secretion in $\mathrm{CF}$ epithelial cells had already been characterized several years before the discovery of the CFTR gene. ${ }^{36}$ Over the past few years, it has become apparent that CFTR-dependent bicarbonate secretion, required for normal expansion of mucins (the main component of mucus), is also defective in patients with $\mathrm{CF}^{37}$ Therefore, the role of CFTR in CF pathogenesis is both due to lack of $\mathrm{Cl}^{-}$, resulting in low hydration of the airway surface liquid, and decrease of $\mathrm{HCO}_{3^{-}}$transport, which maintain mucins in an aggregated and poorly soluble form.

In addition to the defective apical $\mathrm{Cl}^{-}$and $\mathrm{HCO}_{3}^{-}$secretion (due to the absence or dysfunction of CFTR), the hyperabsorption of $\mathrm{Na}^{+}$through hyperactive epithelial sodium channel $(\mathrm{ENaC})$ is another hallmark of $\mathrm{CF}$ epithelia. ${ }^{36}$ The failure of mutated CFTR proteins to regulate $\mathrm{ENaC}$ activity is proposed to play a major role in the pathophysiology of CF lung disease. ${ }^{38-40}$ How does CFTR regulate ENaC and how much CFTR is needed to do so is still debated. ${ }^{41,42}$ It has been reported that CFTR and $\mathrm{ENaC}$ physically interact in several cell types. ${ }^{43-45}$ CFTR could also decrease the open probability of $\mathrm{ENaC},{ }^{46,47}$ possibly by protecting $\mathrm{ENaC}$ against endogenous proteolytic cleavage. ${ }^{48}$ Finally, CFTR could modulate $\mathrm{ENaC}$ stability at the plasma membrane ${ }^{49}$ or regulate the electric coupling between the two channels. ${ }^{50,51}$

CFTR controls many other ion channels and transporters. ${ }^{52}$ Besides its own ability to transport $\mathrm{Cl}^{-}$and $\mathrm{HCO}_{3}^{-}$, CFTR indirectly modulates the transports of these ions by regulating, for instance, several members of the solute carrier 26 (SLC26) family. ${ }^{53}$ While some of these proteins function as $\mathrm{Cl}^{-} / \mathrm{HCO}_{3}{ }^{-}$exchange proteins and participate in $\mathrm{pH}$ regulation, SLC26A9 is a chloride channel expressed in the apical membrane of epithelial cells and is constitutively active in human bronchial epithelial cells (HBECs) ${ }^{54-56}$ It contributes to cAMP-dependent chloride secretion and its activity is maximal when coexpressed with wild-type (WT) CFTR. ${ }^{55}$

\section{Classes of CFTR mutations}

Six classes of CFTR mutations have been described (Table 1). Mutations of classes I, II, III, and VI are considered as severe as they are associated with little to no CFTR protein at the plasma membrane, while mutations of classes IV and $\mathrm{V}$ generate milder phenotypes as they lead to only partial loss of CFTR activity. ${ }^{57,58}$

Class I mutations are nonsense mutations causing defects in mRNA splicing or premature insertion of a stop codon in the polypeptidic chain synthesis. They account for $\sim 10 \%$ of the CFTR mutations worldwide and are particularly prevalent in the Ashkenazi Jewish population where they reach $50 \%$ of CFTR alleles, with $\mathrm{W} 1282 \mathrm{X}$ being the most frequent mutation of this population. ${ }^{59}$

Class II mutations cause defective protein processing and trafficking to the plasma membrane. Among these, the most common CF allele F508del-CFTR is found in $\sim 70 \%$ of the patients (The Clinical and Functional Translation of CFTR [CFTR2]; http://cftr2.org). The deletion of the phenylalanine at position 508 of the CFTR protein causes CFTR misfolding and prolonged retention of the protein in the endoplasmic reticulum, followed by rapid degradation by the ubiquitinproteasome pathway. ${ }^{60,61}$

Class III mutations are relatively rare mutations characterized by altered gating and reduced open probability of the channel. The G551D mutation, also known as the Celtic mutation, is the prototype of class III mutation and represent $\sim 2 \%-3 \%$ of CF alleles in north west and central Europe but is less common in other parts of Europe. ${ }^{62}$

Class IV mutant proteins are correctly inserted at the plasma membrane but the channel single conductance is altered. The most frequent class IV mutations encountered in patients are $\mathrm{R} 117 \mathrm{H}$ (1.3\%) and R347P (0.37\%).

Class V (eg, A455E and 2789+5G $\rightarrow$ T) and VI $(\mathrm{eg}$, 4326delTC and 4279insA) mutations lead to reduced amount of CFTR protein at the plasma membrane, by affecting CFTR mRNA (stability, alternative splicing, etc) or increasing the turnover of the CFTR protein, respectively.

Some CFTR mutations display more than one type of dysfunctions. For example, in addition to trafficking defect, F508del-CFTR also presents with characteristic defects of classes III and IV, with a reduced open probability ${ }^{63}$ and decreased membrane stability, ${ }^{64}$ respectively. 
Table I Classes of CFTR mutations

\begin{tabular}{|c|c|c|c|c|c|c|}
\hline Class & Class I & Class II & Class III & Class IV & Class V & Class VI \\
\hline Type of defect & $\begin{array}{l}\text { No functional } \\
\text { protein }\end{array}$ & $\begin{array}{l}\text { Trafficking } \\
\text { defect }\end{array}$ & $\begin{array}{l}\text { Defective channel } \\
\text { regulation }\end{array}$ & $\begin{array}{l}\text { Decreased channel } \\
\text { conductance }\end{array}$ & Reduced synthesis & $\begin{array}{l}\text { Decreased } \\
\text { stability }\end{array}$ \\
\hline Examples of & G542X & F508del & G55ID & RII7H & $3849+10 \mathrm{kbC} \rightarrow \mathrm{T}$ & 4326delTC \\
\hline \multirow[t]{3}{*}{ mutations } & WI282X & NI303K & GI78R & R347P & $2789+5 G \rightarrow A$ & Q14I2X \\
\hline & R553X & I507del & G55IS & RII7C & $3120+I G \rightarrow A$ & 4279insA \\
\hline & $62 \mathrm{I}+\mathrm{IG} \rightarrow \mathrm{T}$ & R560T & S549N & R334W & $5 T$ & \\
\hline
\end{tabular}

Abbreviation: CFTR, cystic fibrosis transmembrane conductance regulator.

\section{First modulators and natural compounds}

The expression and activity of CFTR channels are regulated by many intracellular signaling pathways. The most known modulator of the CFTR chloride channel is intracellular cAMP, and the activity of CFTR is mainly regulated via phosphorylation by various protein kinases and dephosphorylation by protein phosphatases.

Naturally occurring compounds inducing phosphorylation of the channel were among the first CFTR modulators identified. ${ }^{65}$ Alkylxanthines, such as caffeine, theophylline, and theobromine, are found in plants such as coffee or chocolate beans or tea leaves. Among them, 3-isobutyl1-methylxanthine inhibits phosphodiesterases (PDEs) to enhance CFTR phosphorylation by preventing its dephosphorylation. ${ }^{66-68}$ Patch clamp single-channel recordings also suggested that some xanthine derivatives can directly activate CFTR channel to increase open probability of the channel independently of cAMP levels ${ }^{69}$ possibly through direct binding to NBD1. ${ }^{70}$

Soybeans and soy food (eg, tofu, soy flour, and soy milk) contain large amount of isoflavones, ${ }^{71}$ such as genistein (5,7-dihydroxy-3-(4-hydroxyphenyl)-4H-1-benzopyran4-one). Genistein is a protein tyrosine kinase inhibitor that was found to activate CFTR, independently from protein kinase A or PDE activity. ${ }^{72}$ In contrast with 3-isobutyl1-methylxanthine, ${ }^{73}$ it does not inhibit PDE activity but it requires CFTR phosphorylation to increase open probability of the channel. ${ }^{72}$ This is particularly true to mutated protein F508del- ${ }^{74,75}$ and G551D-CFTR ${ }^{75}$ channels for which genistein restores phosphorylation-dependent activation of the channel by direct binding to NBD1. ${ }^{76}$

Curcumin exhibits structural similarities to isoflavones and might bind directly to CFTR protein ${ }^{77}$ to rescue F508delCFTR trafficking in vitro. ${ }^{78,79}$ In vivo, curcumin increased survival rate of F508del-CFTR mice by preventing gastrointestinal obstruction in treated animals as compared with controls. ${ }^{80}$ Moreover, curcumin corrects CFTR-dependent $\mathrm{Cl}^{-}$ transport across nasal and rectal epithelium of F508del-CFTR mice. ${ }^{80}$ These effects are still controversial as many other studies failed to reproduce them. ${ }^{81,82}$

Resveratrol is a natural polyphenol compound with antioxidant and anti-inflammatory properties that has been shown to activate CFTR-mediated chloride transport in epithelial cells in vitro ${ }^{83,84}$ and in vivo ${ }^{85-87}$ independently from $[\mathrm{cAMP}]_{\mathrm{i}}$ or $\mathrm{R}$ domain phosphorylation. ${ }^{87}$ Two independent studies also demonstrated that resveratrol corrects F508delCFTR trafficking in CF cell lines ${ }^{88}$ and in CF mouse models. ${ }^{86}$ However, doses required for such effects might be difficult to achieve in vivo. ${ }^{89}$

Very low cytotoxicity and high abundance of natural compounds in regular aliment make them an appealing therapeutic option. It seems difficult to achieve sufficiently high concentration of these compounds from food intake only; therefore, administering purified compounds at higher doses could be considered. They may not be selective enough, however, as they often regulate various cellular and biochemical functions.

\section{Drug repositioning}

The goal of drug repositioning is to identify new indications of marketed drugs in particular for rare and neglected diseases. ${ }^{90}$ They have multiple advantages over innovative treatments: they are considered safer, as they have already undergone extensive toxicology and safety assessment, they are often less expensive, and shortage is less likely to occur.

Iminosugars that interfere with $N$-glycosylation are approved for the treatment of Gaucher disease. ${ }^{91}$ Although strong in vitro ${ }^{92,93}$ and preclinical evidence ${ }^{92,94}$ demonstrated that $\mathrm{N}$-butyldeoxynojirimycin (miglustat, Zavesca ${ }^{\circledR}$ ) corrects both $\mathrm{Cl}^{-}$and $\mathrm{Na}^{+}$transport by restoring the trafficking defect of F508del-CFTR, a Phase II clinical trial failed to demonstrate significant changes in chloride transport measured by nasal potential difference (NPD), sweat chloride, or force expiratory volume in 1 second $\left(\mathrm{FEV}_{1}\right)$ in CF patients. ${ }^{95}$

PDE5 inhibitors (iPDE5) and soluble guanylyl cyclase activators are currently approved for the treatment of erectile dysfunction ${ }^{96}$ and pulmonary hypertension. ${ }^{97}$ They both lead 
to increased intracellular cGMP content, although the final mechanism of action on CFTR is still unknown. Some data suggested two distinct effects: a cGMP-dependent increase in CFTR activity and a cGMP-independent effect on CFTR trafficking. ${ }^{98}$ Some in vitro studies required 1,000 -fold greater concentration than what is used in the clinic to observe an effect on CFTR trafficking. ${ }^{98,99}$ In vivo preclinical studies have yet showed that improvement in chloride transport could be achieved with clinical doses of iPDE5, such as sildenafil and vardenafil, in CF mice. ${ }^{100,101}$ Outcomes of a Phase IIa open-label study aiming at investigating safety and efficacy of sildenafil in CF lung disease were recently published. ${ }^{102}$ No change in sputum IL-8 was noted, but sputum neutrophil elastase content was significantly reduced after treatment. However, pharmacokinetic profiles of sildenafil suggested that $\mathrm{CF}$ patients may eliminate sildenafil at a faster rate than non-CF patients.

Similar to iPDE5, riociguat (BAY 63-2521) increases intracellular cGMP levels in a concentration-dependent manner and in synergy with nitric oxide (NO). ${ }^{103,104}$ It is a soluble guanylate cyclase activator developed by Bayer, already approved for pulmonary arterial hypertension. A Phase II trial is currently ongoing for adult $\mathrm{CF}$ patients homozygous for F508del mutation (NCT02170025).

Ibuprofen has long been known for its anti-inflammatory properties, and has been showed to significantly slow the decline in $\mathrm{FEV}_{1}$ in $\mathrm{CF}$ patients. ${ }^{105}$ This effect was solely attributed to its anti-inflammatory effect. However, a recent in vitro study demonstrated that ibuprofen is also an efficient F508del-CFTR corrector via inhibition of cyclooxygenase- $1 .{ }^{106}$

Approved for the treatment of cystinosis, ${ }^{107}$ cysteamine is a proteostasis regulator that restores autophagy, which is defective in CF. ${ }^{108,109}$ This is associated with a rescue and stabilization of F508del-CFTR at the plasma membrane. ${ }^{10,111}$ Given orally together with epigallocatechin gallate (EGCG, a flavonoid derived from green tea, contained in dietary supplements), cysteamine significantly reduced sweat chloride levels and levels of pro-inflammatory markers TNF- $\alpha$ and IL- 8 during a small pilot study in homozygous F508del-CFTR patients. ${ }^{111}$ An open-label Phase II trial involving 34 patients met the primary end point of efficacy, with a significant reduction in sweat chloride concentration of $-18.0 \mathrm{mmol} / \mathrm{L}$, but no significant difference in $\mathrm{FEV}_{1}$ was observed. ${ }^{112}$

Escin, extracted from horse chestnut tree, possesses anti-inflammatory effects and is already used in patients with chronic venous insufficiency, hemorrhoids, and posttraumatic edema. ${ }^{113}$ Escin significantly enhanced CFTR function in Fisher rat thyroid cells transfected with different CFTR class I mutants (G542X, W1282X) and in primary HBECs isolated from G542X/F508del and W1282/F508del patients. ${ }^{114}$ By contrast, escin failed to improve CFTR function in HBECs from a patient homozygous for F508del, demonstrating that Escin acts as a readthrough agent for nonsense mutations.

All these compounds are excellent illustrations that, as for many other rare diseases, CF therapy may benefit from drug repositioning as a strategy to speed up drug development.

\section{Genotype-specific therapies}

With the development of high-throughput screening (HTS) assays allowing rapid screening of thousands of small molecules, many families of chemical structures have been identified. Thanks to expanding knowledge of the structure and function of CFTR, and to increased understanding of the different functional consequences of CFTR mutations, structure-activity relationship and optimization of the most promising lead compounds have led to a series of potential pharmacological therapies for CF to correct CFTR defects at different levels. ${ }^{114-117}$ CFTR modulators can be categorized according to the class of mutation or dysfunction that they aim at targeting (Figure 3 and Table 2).

\section{Therapies targeting class I}

Development of premature termination codon (PTC) "readthrough" agents allow ribosomes to continue translation through class I nonsense mutations to produce full-length CFTR protein. Almost 20 years ago, aminoglycosides, such as gentamicin, were first described as a potential pharmacological approach for class I mutations. ${ }^{118-120}$ In addition to its potent bactericidal activity, gentamicin displayed beneficial effects on electrophysiological parameters assessed by NPD in vivo after topical nasal application ${ }^{121,122}$ or intravenous administration $^{118,123}$ in CF patients with at least one class I mutation. However, high inter-individual variability in clinical benefits was observed, in particular between patients carrying only one and those carrying two nonsense mutations. ${ }^{124}$ In addition, high nephron- and oto-toxicity render per os or systemically administered aminoglycosides not well suited for long-term use. To tackle this, new series of synthetic aminoglycoside derivatives were developed through a systematic structurebased approach. ${ }^{125,126}$ NB30, NB54, and NB124 had significantly reduced toxicity ${ }^{125,127}$ and demonstrated superior in vitro readthrough activity in HBE cell lines or primary cells expressing at least one nonsense CFTR mutation. ${ }^{125,128}$ Moreover, when systemically administrated to $\mathrm{cftr}^{-/-}$mice expressing human 


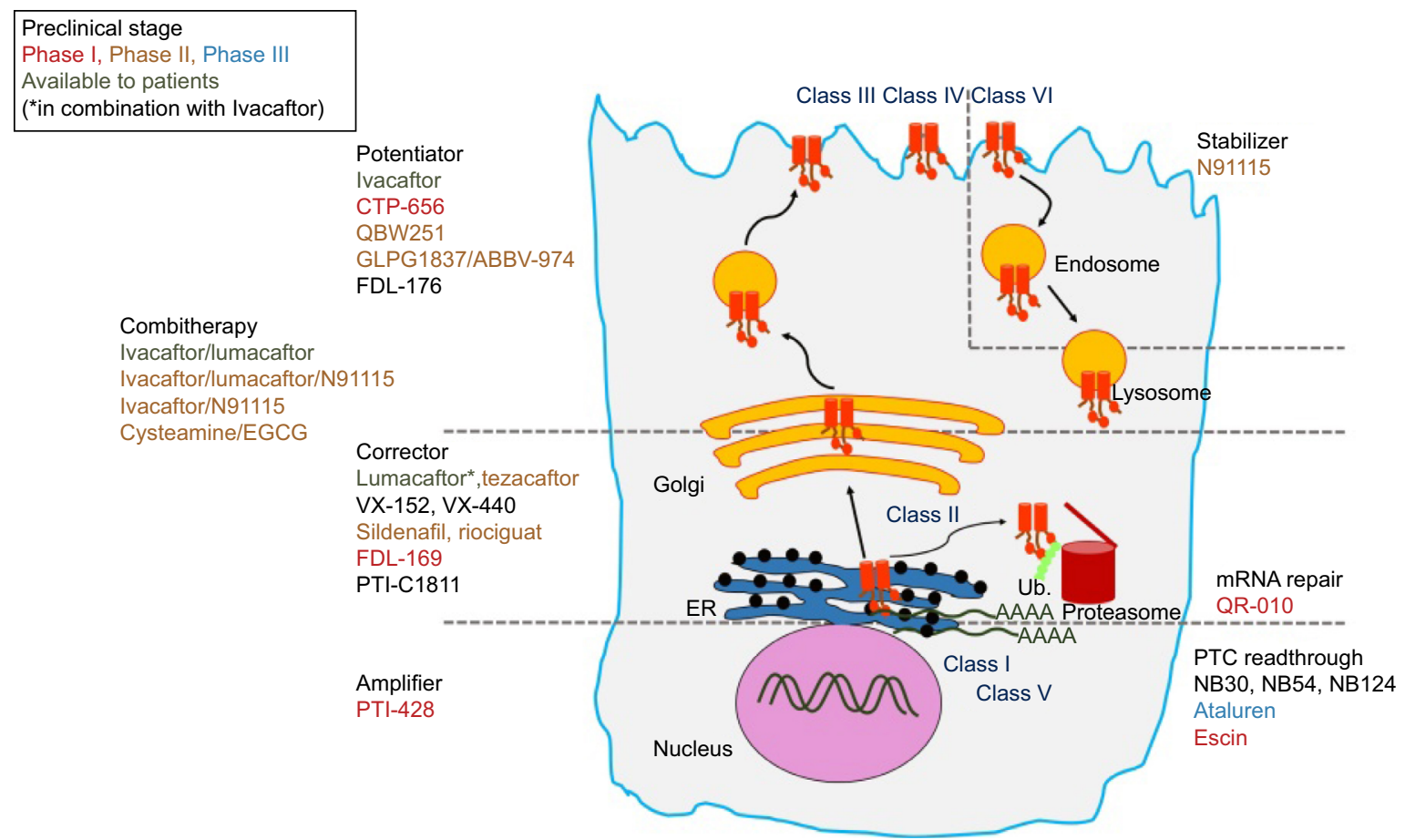

Figure 3 Overview of the most advance CFTR modulators in preclinical and clinical studies, with regard to the class of CFTR mutations and the primary defect of the corresponding mutant protein.

Abbreviations: CFTR, cystic fibrosis transmembrane conductance regulator; PTC, premature termination codon; EGCG, epigallocatechin gallate; ER, endoplasmic reticulum; Ub, ubiquitin; mRNA, messenger RNA.

CFTR-G542X, ${ }^{129}$ NB54 and NB124 restored CFTR activity measured ex vivo across intestinal epithelium to at least 5\% of the current observed in WT animals. ${ }^{127,128}$

Through HTS, PTC Therapeutics ${ }^{\text {TM }}$ (Dublin, Ireland) identified PTC-124 (3-[5-(2-fluorophenyl)-1,2,4-oxadiazol3 -yl]-benzoic acid), ataluren. It is an orally bioavailable small molecule inducing complete translation of proteins containing premature nonsense mutations without affecting the normal stop codons. ${ }^{130}$ In the initial Phase II trial, CF adults with at least one CFTR nonsense mutation received oral treatment with ataluren for 14 days followed by a washout period of 14 days. ${ }^{131}$ CFTR function measured by NPD was restored and a small decrease in $\mathrm{ENaC}$ activity was also recorded. Moreover, patients presented with slight increase in $\mathrm{FEV}_{1}$ and bodyweight, and some of them reported an improvement in pulmonary symptoms such as cough. A pediatric trial was conducted with children of age 6 and older, and demonstrated similar improvements in CFTR function although it did not correlate with $\mathrm{FEV}_{1} \cdot{ }^{132}$ Despite these encouraging data, ataluren did not provide a significant improvement in $\mathrm{FEV}_{1}$ of a Phase III placebo-controlled trial. ${ }^{133}$ Interaction with chronically inhaled tobramycin could be a cause, as the subgroup of patients not receiving inhaled aminoglycosides showed a more robust improvement in $\mathrm{FEV}_{1}(+5.7 \%$ predicted) together with fewer pulmonary exacerbations $(-40 \%)$ in the ataluren group as compared to the placebo. Moreover, variable responses were found among patients with different genotypes suggesting that readthrough agents may not work for all class I mutations.

\section{Therapies targeting class II}

The aim of class II targeting compounds is to rescue the trafficking defect of mutant CFTR and therefore increase the quantity of mutated CFTR protein inserted in the plasma membrane. Soon after the identification of the CFTR gene, Denning et $\mathrm{al}^{61}$ demonstrated that low-temperature incubation (eg, $27^{\circ} \mathrm{C}$ ) restores F508del-CFTR expression at the plasma membrane. This was the first evidence that the trafficking defect of F508del-CFTR could be modified to allow partial escape from the endoplasmic reticulum quality control and functional expression on the cell surface. Additional in vitro proofs of mutant CFTR druggability were obtained with chemical chaperones ${ }^{134,135}$ or the transcriptional regulator butyrate. ${ }^{136}$ In vitro, 4-phenylbutyrate (4-PBA), an analog of butyrate, corrects the trafficking defect of F508del-CFTR ${ }^{137}$ by modulating the interaction with $70 \mathrm{kDa}$ Heat shock protein (Hsp) family Hsc70. ${ }^{138}$ 4-PBA was one of the first corrector to be tested in a pilot clinical trial for $\mathrm{CF}$, where it slightly improved CFTR activity in nasal epithelium but did not reduce sweat chloride concentration. ${ }^{139}$ 
Table 2 Mechanisms of action of pharmacological modulators of CFTR available to CF patients or under preclinical development as mono- and/or combitherapies for CF

\begin{tabular}{|c|c|c|c|c|}
\hline \multicolumn{2}{|c|}{ Classes of compounds } & \multirow{2}{*}{$\begin{array}{l}\text { Target } \\
\begin{array}{l}\text { Class I (nonsense } \\
\text { mutations) }\end{array}\end{array}$} & \multirow{2}{*}{$\begin{array}{l}\text { Mechanism of action } \\
\text { Generate a full-length CFTR by complete } \\
\text { translation of CFTR transcript }\end{array}$} & \multirow{2}{*}{$\begin{array}{l}\text { Pharmacological } \\
\text { compounds } \\
\text { Ataluren } \\
\text { Escin } \\
\text { NB30, NB54, NBI24 }\end{array}$} \\
\hline Monotherapies & PTC read-through & & & \\
\hline & mRNA repair therapy & All classes & $\begin{array}{l}\text { Repair the CFTR mRNA to generate a WT- } \\
\text { CFTR transcript }\end{array}$ & $\begin{array}{l}\text { QR-0I0 (specific for } \\
\text { F508del-CFTR) }\end{array}$ \\
\hline & Correctors & Class II & Rescue F508del-CFTR to the plasma membrane & $\begin{array}{l}\text { Lumacaftor, tezacaftor, } \\
\text { VX-I52, VX-440 } \\
\text { Sildenafil, riociguat } \\
\text { FDL-169 } \\
\text { PTI-CI8II }\end{array}$ \\
\hline & Potentiators & $\begin{array}{l}\text { Class III } \\
\text { Class IV }\end{array}$ & Bind to CFTR to increase open probability & $\begin{array}{l}\text { Ivacaftor } \\
\text { CTP-656 } \\
\text { QBW25I } \\
\text { GLPG I837/ABBV-974 } \\
\text { FDL- } 176\end{array}$ \\
\hline \multirow[t]{6}{*}{ Combitherapies } & Corrector/potentiator & Class II/III & $\begin{array}{l}\text { Rescue F508del-CFTR to the plasma } \\
\text { membrane, increase CFTR open probability }\end{array}$ & $\begin{array}{l}\text { Lumacaftor/ivacaftor } \\
\text { Tezacaftor/ivacaftor } \\
\text { Lumacaftor/QBW25I }\end{array}$ \\
\hline & $\begin{array}{l}\text { Corrector 1/corrector } 2 / \\
\text { potentiator }\end{array}$ & Class II/III & $\begin{array}{l}\text { Rescue F508del-CFTR to the plasma membrane } \\
\text { via two distinct mechanisms and increase CFTR } \\
\text { open probability }\end{array}$ & $\begin{array}{l}\text { Tezacaftor/VX-152/ivacaftor } \\
\text { Tezacaftor/VX-440/ivacaftor }\end{array}$ \\
\hline & Corrector/stabilizer & Class II & $\begin{array}{l}\text { Rescue F508del-CFTR to the plasma membrane } \\
\text { and enhance rescued F508del-CFTR stability }\end{array}$ & Cysteamine/EGCG \\
\hline & Corrector/potentiator/stabilizer & Class II/III/VI & $\begin{array}{l}\text { Rescue F508del-CFTR to the plasma } \\
\text { membrane, increase CFTR open probability, } \\
\text { and enhance rescued F508del-CFTR stability }\end{array}$ & Lumacaftor/ivacaftor/N9III5 \\
\hline & Potentiator/stabilizer & Class VI & $\begin{array}{l}\text { Increase CFTR open probability and enhance } \\
\text { rescued F508del-CFTR stability }\end{array}$ & Ivacaftor/N9III5 \\
\hline & Amplifier/other modulator(s) & All classes & $\begin{array}{l}\text { Increase the amount of immature CFTR to } \\
\text { provide more substrate for other modulators } \\
\text { to act upon }\end{array}$ & PTI-428/other(s) \\
\hline
\end{tabular}

Abbreviations: CFTR, cystic fibrosis transmembrane conductance regulator; CF, cystic fibrosis; PTC, premature termination codon; mRNA, messenger RNA; WT, wild type.

With the development of HTS assays and medicinal chemistry, many families of new chemical structures with corrector properties have emerged. Their corrector activities are exerted through direct modulation of protein folding ${ }^{140,141}$ or cellular proteostasis, ${ }^{142}$ or may act as pharmacological chaperons. ${ }^{143}$ While many of the compounds available so far, such as corr-4a ${ }^{116}$ or VRT-325, ${ }^{141}$ will never progress beyond the status of "bench tools", some hits have been identified and optimized in view of clinical assessments. The most advanced corrector for F508del-CFTR is VX-809 (lumacaftor), developed by Vertex Pharmaceuticals (Boston, MA, USA). VX-809 restores F508del-CFTR trafficking by improving its folding and stabilizing membrane-spanning domain $1 .{ }^{144,145}$ Four weeks of oral lumacaftor as monotherapy in homozygous F508del-CFTR patients was demonstrated safe and well tolerated. ${ }^{146}$ Sweat chloride contents were significantly decreased with treatment in a dose-dependent manner. However, lumacaftor failed to demonstrate any therapeutic benefit for lung function as it did not change
$\mathrm{FEV}_{1}$ nor modulate NPD parameters. This lack of clinical effect suggested that corrector-based monotherapies are not efficient enough to improve lung function because they do not target the other biological defects of F508del-CFTR, ie, decreased membrane stability and open probability.

Because in vitro studies showed that CFTR potentiator VX-770 (see ivacaftor, classes III and IV) improved the open probability of VX-809-rescued F508del-CFTR, ${ }^{145}$ a new Phase II $^{147}$ and a Phase III ${ }^{148}$ studies with combination of lumacaftor and ivacaftor were conducted. Overall, the absolute increase in $\mathrm{FEV}_{1}$ was modest $(+3 \%) .{ }^{148}$ Currently marketed as Orkambi ${ }^{\circledR}$, the ivacaftor-lumacaftor combination has been heavily challenged because it seems no more efficient that conventional multitherapies ${ }^{149}$ for a price outrageously tenfold higher. ${ }^{150}$ More importantly, two in vitro studies evidenced negative interference between ivacaftor and several correctors including lumacaftor, as prolonged exposure of HBECs with ivacaftor decreases the stability of lumacaftor-corrected F508del-CFTR. ${ }^{151,152}$ This could explain 
in part the modest improvement of lung function observed in patients taking lumacaftor/ivacaftor.

Vertex Pharmaceuticals is currently expanding its drug portofolio by developing more correctors such as VX-661 (tezacaftor), for which they claimed slightly better clinical efficacy $\left(+4.8 \% \mathrm{FEV}_{1}\right)$ than VX-809 when combined with ivacaftor in patients with two copies of F508del-CFTR. ${ }^{153}$ Moreover, VX-661 showed additional benefit (+4.6\% FEV $\left.{ }_{1}\right)$ in patients carrying both F508del- and G551D-CFTR mutations and who were already taking ivacaftor. ${ }^{153}$

More next-generation correctors such as VX-152 and VX-440 will be evaluated in combination with VX-661/ ivacaftor as triple combinations (VX-152/VX-661/ivacaftor and VX-440/VX-661/ivacaftor) in homozygous F508del patients and patients with one F508del associated with a second mutation that results in minimal CFTR function. In vitro, these triple combinations resulted in an increase in chloride transport in HBECs approximately threefold higher than with lumacaftor/ivacaftor.

Other drug discovery companies have undertaken development of correctors. Among them, PTI-C1811 (Proteostasis Therapeutics, Cambridge, MA, USA) and FDL-169 (Flatley Discovery Lab, Charlestown, MA, USA) act through different mechanisms than VX-809 and are both claimed to have similar or superior in vitro activity when combined with potentiators.

Unlike CFTR correctors that act at the protein level, ProQR Therapeutics NV (Leiden, the Netherlands) developed QR-010, a single-strand modified RNA specifically designed to repair the F508del mutation at the mRNA level to generate a WT-CFTR transcript. In vivo in a preclinical mouse model, QR-010 demonstrated a robust increase in CFTR activity measured by $\mathrm{NPD}^{154}$ and a restoration of CFTR-dependent salivary secretion rates. ${ }^{155}$ QR-010 is now being tested in two clinical trials. In a Phase Ib study (NCT02532764), single and multiple ascending doses will assess QR-010 safety and tolerability in F508del homozygous patients. The second study (NCT02564354) is exploratory proof-of-concept study in CF patients with at least one copy of F508del. It will explore whether intranasal administration of QR-010 can restore function of the CFTR protein as measured by NPD.

\section{Therapies targeting class III and IV}

Class III and IV mutations are considered mild because they produce full-length CFTR that inserts into the plasma membrane where it can correctly interact with other proteins. However, chloride transport is reduced because the open probability (class III) or the single conductance (class IV) of the channel is altered. Pharmacological compounds that enhance CFTR function at the cell membrane are called potentiators.

VX-770 (ivacaftor) was identified by HTS in epithelial cells expressing G551D-CFTR. ${ }^{156}$ Early clinical investigations enrolling patients with at least one G551D mutations provided encouraging efficacy data (as measured by NPD and sweat chloride concentration) in patients receiving $150 \mathrm{mg}$ ivacaftor twice a day, together with a safety profile comparable to the placebo group. ${ }^{157}$ Longer studies (STRIVE and ENVISION), up to 48 weeks, also demonstrated that patients aged 6 years and older treated with ivacaftor gained significantly more weight and their frequency of pulmonary exacerbation was reduced by $55 \%$ with ivacaftor as compared to placebo. ${ }^{158,159}$ During the KONNECTION study, ivacaftor resulted in significant improvement in $\mathrm{FEV}_{1}(+10.7 \%$ at 8 weeks), sweat chloride, and body mass index in patients carrying one of the following non-G551D alleles: G178R, S549N, S549R, G551S, G970R, G1244E, S1251N, S1255P, or G1349D. ${ }^{160}$ Results were comparable to those observed during the STRIVE and ENVISION studies $\left(+10.6 \% \mathrm{FEV}_{1}\right)$ in patients with G551D mutation. ${ }^{158,159}$

Because CF lung disease is progressive, treating patients as early as possible was the aim of the KIWI study which enrolled preschoolers (2.5-5 years old) with one G551D mutation. Ivacaftor seemed to be safe in that cohort, although extended results are awaited. ${ }^{161}$

During the initial screening, ivacaftor was shown to also potentiate activity of rescued F508del-CFTR. ${ }^{156}$ As expected with a potentiator, a clinical trial with ivacaftor for F508del/ F508del patients failed to support its use as a monotherapy for this class of patients. ${ }^{162}$ As of now, ivacaftor (Kalydeco®; Vertex Pharmaceuticals) is the only potentiator approved for CF patients aged 2 years and older who carry at least one of the following mutations: G551D, G1244E, G1349D, G178R, G551S, S1251N, S1255P, S549N, S549R or R117H. Ivacaftor is seen by the CF community as a proof of principle of clinical benefit from a CFTR modulator, and its approval was a very significant milestone in $\mathrm{CF}$ treatment.

Concert Pharmaceuticals Inc. (Lexington, MA, USA) is applying deuterium chemistry to enhance the pharmacokinetic properties of ivacaftor. This approach was tested in CF patients with class III mutations in a Phase I crossover comparison of deuterated ivacaftor (CTP-656) vs ivacaftor. CTP-656 demonstrated a longer half-life of the compound in plasma compared to ivacaftor, supporting the possibility to reduce the dosing to once a day. ${ }^{163}$ 
QBW251 is a potentiator developed by Novartis Pharmaceuticals. In vitro data showed superior efficacy of QBW251 as compared to ivacaftor when both are combined with lumacaftor. Phase II trial (NCT02190604) has been conducted and some outcomes have been recently presented. ${ }^{164} \mathrm{CF}$ heterozygous patients with at least one class III to VI mutation were enrolled (including patients with one F508del mutation as it can be considered either as class II, III, or VI). A separate arm of the study enrolled only F508del-CFTR homozygous patients. Orally administered QBW251 (150 mg or $450 \mathrm{mg}$, twice a day) for 2 weeks was safe and well tolerated in the 40 CF patients. ${ }^{164}$ In patients with a residual function, QBW251 (450 mg) statistically increased $\mathrm{FEV}_{1}$ over placebo by $7.3 \%$, an increase that is considered as clinically relevant for lung function and very similar to that observed with ivacaftor. As for ivacaftor, QBW251 monotherapy did not demonstrate any efficacy in patients with two copies of F508del.

The potentiator GLPG1837/ABBV-974 is codeveloped by Galapagos NV (Mechelen, Belgium) and AbbVie Pharmaceuticals (North Chicago, IL, USA). Phase I has demonstrated that single (up to $2 \mathrm{~g}$ ) and multiple doses (up to $800 \mathrm{mg}$ twice a day for 14 days) of GLPG1837/ABBV-974 were safe and well tolerated in healthy volunteers. ${ }^{165}$ Two Phase II open-label studies are ongoing and will explore GLPG1837/ ABBV-974 safety, tolerability, and efficacy in CF patients with G551D (SAPHIRA1) and S1251N (SAPHIRA2).

\section{Therapies targeting class $\mathrm{V}$ and $\mathrm{VI}$}

Currently, there is no clinical data available for class V-specific therapies. For class VI, a new class of compounds increasing the half-life of CFTR protein at the plasma membrane has recently attracted interest. VRT-325 and Corr-4a were prototypes for this type of compounds, so-called "stabilizers", which are meant to be complementary to existing and future CFTR modulators.

N91115, developed by Nivalis Therapeutics (Boulder, CO, USA), is an inhibitor of $S$-nitroglutathione (GSNO) reductase and aimed at increasing intracellular levels of GSNO. GSNO induces the $S$-nitrosylation of the cellular chaperone Hsp70/Hsp90 organizing protein which prevents the association of CFTR with Hsp70/Hsp90 organizing protein. ${ }^{166-168} \mathrm{~N} 91115$ was proven safe and well tolerated in CF patients with two F508del alleles. ${ }^{169} \mathrm{~N} 91115$ has recently received the status of Orphan Drug designation by the FDA and two Phase II clinical studies are ongoing (see "Combitherapies and personalized medicine" section). In the near future, potentiators may also prove useful to provide maximal activation of class VI mutants.

\section{Combitherapies and personalized medicine}

Many pharmacological agents are currently in development to correct mutant CFTR activity in CF. These agents are becoming increasingly specific, and aim at targeting patients with particular genotype. The most advance treatment for CF currently available for patients is ivacaftor. This is a typical example of personalized medicine where only individuals with specific mutations can be treated with this drug. Although ivacaftor provides a significant improvement in lung function, this may not be achievable in every CF patient with a single compound. More specifically, in patients carrying CFTR mutations displaying multiple dysfunctions, such as F508del-CFTR, combination of several molecules will likely lead to better clinical results. Here, the biological defects of F508del-CFTR could be ideally addressed by a triple combination of a corrector to increase the amount of F508del-CFTR protein expressed in the plasma membrane, a potentiator to enhance its open probability and a stabilizer to increase its half-life at the plasma membrane.

To tackle the membrane instability of rescued F508delCFTR, Nivalis is currently evaluating N91115 safety and efficacy in combination with lumacaftor/ivacaftor in homozygous F508del patients (NCT02589236) and with ivacaftor in patients with one F508del and a gating mutation (NCT02724527) in two Phase II clinical trials.

Another new class of compounds is currently investigated by Proteostasis Therapeutics. They are developing PTI-428, a CFTR amplifier, which aims to selectively increase the amount of immature form of CFTR protein to provide other CFTR modulators with more substrate to act upon. ${ }^{170} \mathrm{PTI}-428$ received Fast Track designation from the FDA and a Phase I is ongoing to assess its safety, tolerability and pharmacokinetics in CF patients (NCT02718495).

In the near future, one can also envisage combitherapies with activators of alternative chloride channels or with inhibitors of the $\mathrm{ENaC} .{ }^{171}$

One of the biggest challenges to implement personalized medicine for CF will be to develop new in vitro models to better predict the individual response of patient to different combinations of treatments. Development and use of experimental materials based on patient tissues (such as airway and intestinal organoids or induced pluripotent stem cells) will hopefully provide new powerful assays to better anticipate the individual clinical benefit of CFTR modulators. 


\section{Conclusion}

Many classes of compounds restoring the function of CFTR mutants have been identified; however, most of them, such as natural compound curcumin, were never translated into therapy mainly because of lack of benefit to patients as well as off-target effects or low bioavailability. Drug repositioning, through the exciting examples of the cystamine/EGCG combination or sildenafil, may speed up the development of novel therapies for CF. Currently, ivacaftor alone or in combination with lumacaftor are the only pharmacological modulators of CFTR approved for the treatment of CF. The combination lumacaftor/ivacaftor has been highly challenged as they do not seem to provide significant improvement in lung function as compared to conventional therapies. Ivacaftor targets only a specific CFTR mutant (G551D-CFTR) which is found in $<2 \%$ of the patients, Finally, these two marketed therapies cost over USD 250,000/year (a tenfold increase as compared to usual multitherapies) for a modest improvement in the quality of life of patients. Thus, there is still a major and urgent need for new molecules and therapeutic approaches to be developed for treating $\mathrm{CF}$.

\section{Acknowledgment}

TL and SN received financial support from the European Commission under the H2020-PHC-13-2014 funding program (PRO-CF-MED, ref. 633545) granted to ProQR Therapeutics NV.

\section{Disclosure}

The authors report no conflicts of interest in this work.

\section{References}

1. Riordan J, Rommens J, Kerem B, et al. Identification of the cystic fibrosis gene: cloning and characterization of complementary DNA. Science. 1989;245(4922):1066-1073.

2. Huaux F, Noel S, Dhooghe B, et al. Dysregulated proinflammatory and fibrogenic phenotype of fibroblasts in cystic fibrosis. PLoS One. 2013;8(5):e64341.

3. Marcorelles P, Friocourt G, Uguen A, Ledé F, Férec C, Laquerrière A. Cystic fibrosis transmembrane conductance regulator protein (CFTR) expression in the developing human brain: comparative immunohistochemical study between patients with normal and mutated CFTR. $J$ Histochem Cytochem. 2014;62(11):791-801.

4. Gao Z, Sun HY, Lau CP, Chin-Wan Fung P, Li GR. Evidence for cystic fibrosis transmembrane conductance regulator chloride current in swine ventricular myocytes. J Mol Cell Cardiol. 2007;42(1):98-105.

5. Bonfield TL, Hodges CA, Cotton CU, Drumm ML. Absence of the cystic fibrosis transmembrane regulator (Cftr) from myeloid-derived cells slows resolution of inflammation and infection. J Leukoc Biol. 2012;92(5):1111-1122.

6. Di A, Brown ME, Deriy LV, et al. CFTR regulates phagosome acidification in macrophages and alters bactericidal activity. Nat Cell Biol. 2006;8(9):933-944.
7. Painter RG, Valentine VG, Lanson NA, et al. CFTR expression in human neutrophils and the phagolysosomal chlorination defect in cystic fibrosis. Biochemistry. 2006;45(34):10260-10269.

8. Zengerling S, Tsui LC, Grzeschik KH, Olek K, Riordan JR, Buchwald M. Mapping of DNA markers linked to the cystic fibrosis locus on the long arm of chromosome 7. Am J Hum Genet. 1987;40(3):228-236.

9. Tsui L, Buchwald M, Barker D, et al. Cystic fibrosis locus defined by a genetically linked polymorphic DNA marker. Science. 1985;230(4729): 1054-1057.

10. Gadsby DC, Vergani P, Csanady L. The ABC protein turned chloride channel whose failure causes cystic fibrosis. Nature. 2006;440(7083): $477-483$.

11. Sebastian A, Rishishwar L, Wang J, et al. Origin and evolution of the cystic fibrosis transmembrane regulator protein R domain. Gene. 2013;523(2): 137-146.

12. Cheng SH, Rich DP, Marshall J, Gregory RJ, Welsh MJ, Smith AE. Phosphorylation of the R domain by cAMP-dependent protein kinase regulates the CFTR chloride channel. Cell. 1991;66(5):1027-1036.

13. Csanády L, Seto-Young D, Chan KW, et al. Preferential phosphorylation of R-domain Serine 768 dampens activation of CFTR channels by PKA. J Gen Physiol. 2005;125(2):171-186.

14. Billet A, Jia Y, Jensen T, Riordan JR, Hanrahan JW. Regulation of the cystic fibrosis transmembrane conductance regulator anion channel by tyrosine phosphorylation. FASEB J. 2015;29(9):3945-3953.

15. Hallows KR, Kobinger GP, Wilson JM, Witters LA, Foskett JK. Physiological modulation of CFTR activity by AMP-activated protein kinase in polarized T84 cells. Am J Physiol Cell Physiol. 2003;284(5):C1297-C1308.

16. Seavilleklein G, Amer N, Evagelidis A, et al. PKC phosphorylation modulates PKA-dependent binding of the $\mathrm{R}$ domain to other domains of CFTR. Am J Physiol Cell Physiol. 2008;295(5):C1366-C1375.

17. Csanády L, Chan KW, Seto-Young D, Kopsco DC, Nairn AC, Gadsby DC. Severed channels probe regulation of gating of cystic fibrosis transmembrane conductance regulator by its cytoplasmic domains. $J$ Gen Physiol. 2000;116(3):477-500.

18. Chappe V, Irvine T, Liao J, Evagelidis A, Hanrahan JW. Phosphorylation of CFTR by PKA promotes binding of the regulatory domain. EMBO J. 2005;24(15):2730-2740.

19. Hegedüs T, Aleksandrov A, Mengos A, Cui L, Jensen TJ, Riordan JR. Role of individual $\mathrm{R}$ domain phosphorylation sites in CFTR regulation by protein kinase A. Biochim Biophys Acta. 2009;1788(6):1341-1349.

20. Wilkinson DJ, Strong TV, Mansoura MK, et al. CFTR activation: additive effects of stimulatory and inhibitory phosphorylation sites in the $\mathrm{R}$ domain. Am J Physiol Lung Cell Mol Physiol. 1997;273(1):L127-L133.

21. Vais H, Zhang R, Reenstra WW. Dibasic phosphorylation sites in the $\mathrm{R}$ domain of CFTR have stimulatory and inhibitory effects on channel activation. Am J Physiol Cell Physiol. 2004;287(3):C737-C745.

22. Bozoky Z, Krzeminski M, Muhandiram R, et al. Regulatory R region of the CFTR chloride channel is a dynamic integrator of phosphodependent intra- and intermolecular interactions. Proc Natl Acad Sci US A. 2013;110(47):E4427-E4436.

23. Bozoky Z, Krzeminski M, Chong PA, Forman-Kay JD. Structural changes of CFTR R region upon phosphorylation: a plastic platform for intramolecular and intermolecular interactions. FEBS J. 2013;280(18): 4407-4416.

24. Farinha CM, Swiatecka-Urban A, Brautigan DL, Jordan P. Regulatory crosstalk by protein kinases on CFTR trafficking and activity. Front Chem. 2016;4:1.

25. Moran O. On the structural organization of the intracellular domains of CFTR. Int J Biochem Cell Biol. 2014;52:7-14.

26. Hwang TC, Sheppard DN. Gating of the CFTR Cl(-) channel by ATPdriven nucleotide-binding domain dimerisation. J Physiol. 2009;587(pt 10):2151-2161.

27. Lewis HA, Buchanan SG, Burley SK, et al. Structure of nucleotidebinding domain 1 of the cystic fibrosis transmembrane conductance regulator. EMBO J. 2004;23(2):282-293. 
28. Vergani P, Lockless SW, Nairn AC, Gadsby DC. CFTR channel opening by ATP-driven tight dimerization of its nucleotide-binding domains. Nature. 2005;433(7028):876-880.

29. Zhou Z, Wang X, Liu HY, Zou X, Li M, Hwang TC. The two ATP binding sites of cystic fibrosis transmembrane conductance regulator (CFTR) play distinct roles in gating kinetics and energetics. J Gen Physiol. 2006;128(4):413-422.

30. Anderson M, Gregory R, Thompson S, et al. Demonstration that CFTR is a chloride channel by alteration of its anion selectivity. Science. 1991;253(5016):202-205.

31. Linsdell P. Mechanism of chloride permeation in the cystic fibrosis transmembrane conductance regulator chloride channel. Exp Physiol. 2006;91(1):123-129.

32. Linsdell P, Hanrahan JW. Adenosine triphosphate-dependent asymmetry of anion permeation in the cystic fibrosis transmembrane conductance regulator chloride channel. J Gen Physiol. 1998;111(4):601-614.

33. Gould NS, Min E, Martin RJ, Day BJ. CFTR is the primary known apical glutathione transporter involved in cigarette smoke induced adaptive responses in the lung. Free Radic Biol Med. 2012;52(7):1201-1206.

34. Linsdell P, Hanrahan JW. Glutathione permeability of CFTR. Am J Physiol Cell Physiol. 1998;275(1):C323-C326.

35. Tang L, Fatehi M, Linsdell P. Mechanism of direct bicarbonate transport by the CFTR anion channel. J Cyst Fibros. 2009;8(2):115-121.

36. Quinton PM. Chloride impermeability in cystic fibrosis. Nature. 1983;301(5899):421-422.

37. Quinton PM. Cystic fibrosis: impaired bicarbonate secretion and mucoviscidosis. Lancet. 2008;372(9636):415-417.

38. Knowles M, Gatzy J, Boucher R. Increased bioelectric potential difference across respiratory epithelia in cystic fibrosis. $N$ Engl J Med. 1981;305(25):1489-1495.

39. Bangel-Ruland N, Tomczak K, Weber WM. Targeting ENaC as a molecular suspect in cystic fibrosis. Curr Drug Targets. 2015;16(9):951-957.

40. Matsui H, Grubb BR, Tarran R, et al. Evidence for periciliary liquid layer depletion, not abnormal ion composition, in the pathogenesis of cystic fibrosis airways disease. Cell. 1998;95(7):1005-1015.

41. Collawn JF, Lazrak A, Bebok Z, Matalon S. The CFTR and ENaC debate: how important is $\mathrm{ENaC}$ in CF lung disease? Am J Physiol Lung Cell Mol Physiol. 2012;302(11):L1141-L1146.

42. Hobbs CA, Da Tan C, Tarran R. Does epithelial sodium channel hyperactivity contribute to cystic fibrosis lung disease? J Physiol. 2013;591(pt 18):4377-4387.

43. Berdiev BK, Cormet-Boyaka E, Tousson A, et al. Molecular proximity of cystic fibrosis transmembrane conductance regulator and epithelial sodium channel assessed by fluorescence resonance energy transfer. $J$ Biol Chem. 2007;282(50):36481-36488.

44. Ji HL, Chalfant ML, Jovov B, et al. The cytosolic termini of the $\beta$ - and $\gamma$ - ENaC subunits are involved in the functional interactions between CFTR and ENaC. J Biol Chem. 2000;275(36):27947-27956.

45. Kunzelmann K, Kiser GL, Schreiber R, Riordan JR. Inhibition of epithelial Na+ currents by intracellular domains of the cystic fibrosis transmembrane conductance regulator. FEBS Lett. 1997;400(3):341-344.

46. Konstas AA, Koch JP, Korbmacher C. cAMP-dependent activation of CFTR inhibits the epithelial sodium channel $(\mathrm{ENaC})$ without affecting its surface expression. Pflügers Arch. 2003;445(4):513-521.

47. Chinet TC, Fullton JM, Yankaskas JR, Boucher RC, Stutts MJ. Mechanism of sodium hyperabsorption in cultured cystic fibrosis nasal epithelium: a patch-clamp study. Am J Physiol Cell Physiol. 1994;266(4):C1061-C1068.

48. Gentzsch M, Dang H, Dang Y, et al. The cystic fibrosis transmembrane conductance regulator impedes proteolytic stimulation of the epithelial $\mathrm{Na}(+)$ channel. J Biol Chem. 2010;285(42):32227-32232.

49. Lu C, Jiang C, Pribanic S, Rotin D. CFTR stabilizes ENaC at the plasma membrane. J Cyst Fibros. 2007;6(6):419-422.

50. Horisberger J-D. ENaC-CFTR interactions: the role of electrical coupling of ion fluxes explored in an epithelial cell model. Pflügers Arch. 2003;445(4):522-528.
51. Kunzelmann K. ENaC is inhibited by an increase in the intracellular $\mathrm{Cl}^{-}$concentration mediated through activation of $\mathrm{Cl}^{-}$channels. Pflügers Arch. 2003;445(4):504-512.

52. Kunzelmann K, Tian Y, Martins JR, et al. Airway epithelial cells - functional links between CFTR and anoctamin dependent $\mathrm{Cl}-$ secretion. Int J Biochem Cell Biol. 2012;44(11):1897-1900.

53. El Khouri E, Touré A. Functional interaction of the cystic fibrosis transmembrane conductance regulator with members of the SLC26 family of anion transporters (SLC26A8 and SLC26A9): physiological and pathophysiological relevance. Int J Biochem Cell Biol. 2014;52:58-67.

54. Loriol C, Dulong S, Avella M, et al. Characterization of SLC26A9, facilitation of Cl- transport by bicarbonate. Cell Physiol Biochem. 2008;22(1-4):015-030.

55. Bertrand CA, Zhang R, Pilewski JM, Frizzell RA. SLC26A9 is a constitutively active, CFTR-regulated anion conductance in human bronchial epithelia. J Gen Physiol. 2009;133(4):421-438.

56. Ousingsawat J, Schreiber R, Kunzelmann K. Differential contribution of SLC26A9 to $\mathrm{Cl}-$ conductance in polarized and non-polarized epithelial cells. J Gen Physiol. 2012;227(6):2323-2329.

57. Haardt M, Benharouga M, Lechardeur D, Kartner N, Lukacs GL. C-terminal truncations destabilize the cystic fibrosis transmembrane conductance regulator without impairing its biogenesis: a novel class of mutation. J Biol Chem. 1999;274(31):21873-21877.

58. Welsh MJ, Smith AE. Molecular mechanisms of CFTR chloride channel dysfunction in cystic fibrosis. Cell. 1993;73(7):1251-1254.

59. Quint A, Lerer I, Sagi M, Abeliovich D. Mutation spectrum in Jewish cystic fibrosis patients in Israel: implication to carrier screening. $\mathrm{Am} \mathrm{J}$ Med Genet A. 2005;136A(3):246-248.

60. Cheng SH, Gregory RJ, Marshall J, et al. Defective intracellular transport and processing of CFTR is the molecular basis of most cystic fibrosis. Cell. 1990;63(4):827-834.

61. Denning GM, Anderson MP, Amara JF, Marshall J, Smith AE, Welsh MJ. Processing of mutant cystic fibrosis transmembrane conductance regulator is temperature-sensitive. Nature. 1992;358(6389):761-764.

62. Bobadilla JL, Macek M, Fine JP, Farrell PM. Cystic fibrosis: a worldwide analysis of CFTR mutations - correlation with incidence data and application to screening. Hum Mutat. 2002;19(6):575-606.

63. Dalemans W, Barbry P, Champigny G, et al. Altered chloride ion channel kinetics associated with the $\Delta \mathrm{F} 508$ cystic fibrosis mutation. Nature. 1991;354(6354):526-528.

64. Varga K, Goldstein RF, Jurkuvenaite A, et al. Enhanced cell surface stability of rescued $\Delta \mathrm{F} 508$ cystic fibrosis transmembrane conductance regulator by pharmacological chaperones. Biochem J. 2008;410(3):555-564.

65. Dey I, Shah K, Bradbury NA. Natural compounds as therapeutic agents in the treatment cystic fibrosis. J Genet Syndr Gene Ther. 2016;7(1):284

66. Drumm M, Wilkinson D, Smit L, et al. Chloride conductance expressed by delta F508 and other mutant CFTRs in Xenopus oocytes. Science. 1991;254(5039):1797-1799.

67. Becq F, Jensen TJ, Chang XB, et al. Phosphatase inhibitors activate normal and defective CFTR chloride channels. Proc Natl Acad Sci U $S$ A. 1994;91(19):9160-9164.

68. Becq F, Fanjul M, Merten M, Figarella C, Hollande E, Gola M. Possible regulation of CFTR-chloride channels by membrane-bound phosphatases in pancreatic duct cells. FEBS Lett. 1993;327(3):337-342.

69. Chappe V, Mettey Y, Vierfond JM, et al. Structural basis for specificity and potency of xanthine derivatives as activators of the CFTR chloride channel. Br J Pharmacol. 1998;123(4):683-693.

70. Cohen BE, Lee G, Jacobson KA, et al. 8-Cyclopentyl-1,3-dipropylxanthine and other xanthines differentially bind to the wild-type and $\Delta$ F508 mutant first nucleotide binding fold (NBF-1) domains of the cystic fibrosis transmembrane conductance regulator. Biochemistry. 1997;36(21):6455-6461.

71. Illek B, Fischer H. Flavonoids stimulate $\mathrm{Cl}$ conductance of human airway epithelium in vitro and in vivo. Am J Physiol Lung Cell Mol Physiol. 1998;275(5):L902-L910. 
72. French PJ, Bijman J, Bot AG, Boomaars WE, Scholte BJ, de Jonge HR. Genistein activates CFTR Cl- channels via a tyrosine kinase- and protein phosphatase-independent mechanism. Am J Physiol Cell Physiol. 1997;273(2):C747-C753.

73. Illek B, Fischer H, Santos GF, Widdicombe JH, Machen TE, Reenstra WW. cAMP-independent activation of CFTR Cl channels by the tyrosine kinase inhibitor genistein. Am J Physiol Cell Physiol. 1995;268(4):C886-C893.

74. Hwang TC, Wang F, Yang IC, Reenstra WW. Genistein potentiates wildtype and delta F508-CFTR channel activity. Am J Physiol. 1997;273(3 pt 1):C988-C998.

75. Illek B, Zhang L, Lewis NC, Moss RB, Dong JY, Fischer H. Defective function of the cystic fibrosis-causing missense mutation G551D is recovered by genistein. Am J Physiol Cell Physiol. 1999;277(4): C833-C839.

76. Moran O, Galietta LJV, Zegarra-Moran O. Binding site of activators of the cystic fibrosis transmembrane conductance regulator in the nucleotide binding domains. Cell Mol Life Sci. 2005;62(4):446-460.

77. Wang W, Bernard K, Li G, Kirk KL. Curcumin opens cystic fibrosis transmembrane conductance regulator channels by a novel mechanism that requires neither ATP binding nor dimerization of the nucleotidebinding domains. J Biol Chem. 2007;282(7):4533-4544.

78. Egan ME, Glockner-Pagel J, Ambrose CA, et al. Calcium-pump inhibitors induce functional surface expression of delF508-CFTR protein in cystic fibrosis epithelial cells. Nat Med. 2002;8(5):485-492.

79. Norez C, Antigny F, Becq F, Vandebrouck C. Maintaining low Ca2+ level in the endoplasmic reticulum restores abnormal endogenous F508del-CFTR trafficking in airway epithelial cells. Traffic. 2006;7(5): $562-573$.

80. Egan ME, Pearson M, Weiner SA, et al. Curcumin, a major constituent of turmeric, corrects cystic fibrosis defects. Science. 2004;304(5670): 600-602.

81. Song Y, Sonawane ND, Salinas D, et al. Evidence against the rescue of defective $\Delta$ F508-CFTR cellular processing by curcumin in cell culture and mouse models. J Biol Chem. 2004;279(39):40629-40633.

82. Grubb BR, Gabriel SE, Mengos A, et al. SERCA pump inhibitors do not correct biosynthetic arrest of $\triangle \mathrm{F} 508 \mathrm{CFTR}$ in cystic fibrosis. Am J Respir Cell Mol Biol. 2006;34(3):355-363.

83. Yang S, Yu B, Sui Y, et al. CFTR chloride channel is a molecular target of the natural cancer preventive agent resveratrol. Pharmazie. 2013;68(9):772-776.

84. Illek B, Lizarzaburu ME, Lee V, Nantz MH, Kurth MJ, Fischer H. Structural determinants for activation and block of CFTR-mediated chloride currents by apigenin. Am J Physiol Cell Physiol. 2000; 279(6):C1838-C1846

85. Alexander NS, Hatch N, Zhang S, et al. Resveratrol has salutary effects on mucociliary transport and inflammation in sinonasal epithelium. Laryngoscope. 2011;121(6):1313-1319.

86. Dhooghe B, Bouckaert C, Capron A, Wallemacq P, Leal T, Noel S. Resveratrol increases F508del-CFTR dependent salivary secretion in cystic fibrosis mice. Biol Open. 2015;4(7):929-936.

87. Woodworth BA. Resveratrol ameliorates abnormalities of fluid and electrolyte secretion in a hypoxia-induced model of acquired CFTR deficiency. Laryngoscope. 2015;125(suppl 7):S1-S13.

88. Hamdaoui N, Baudoin-Legros M, Kelly M, et al. Resveratrol rescues cAMP-dependent anionic transport in the cystic fibrosis pancreatic cell line CFPAC1. Br J Pharmacol. 2011;163(4):876-886.

89. Jai Y, Shah K, Bridges RJ, Bradbury NA. Evidence against resveratrol as a viable therapy for the rescue of defective $\triangle$ F508 CFTR. Biochim Biophys Acta. 2015;1850(11):2377-2384.

90. Hay Mele B, Citro V, Andreotti G, Cubellis MV. Drug repositioning can accelerate discovery of pharmacological chaperones. Orphanet J Rare Dis. 2015;10:55

91. Sawkar AR, Cheng WC, Beutler E, Wong CH, Balch WE, Kelly JW. Chemical chaperones increase the cellular activity of N370S $\beta$-glucosidase: a therapeutic strategy for Gaucher disease. Proc Natl Acad Sci U S A. 2002;99(24):15428-15433.
92. Noël S, Wilke M, Bot AGM, De Jonge HR, Becq F. Parallel improvement of sodium and chloride transport defects by miglustat (n-butyldeoxynojyrimicin) in cystic fibrosis epithelial cells. J Pharmacol Exp Ther. 2008;325(3):1016-1023.

93. Norez C, Noel S, Wilke M, et al. Rescue of functional delF508-CFTR channels in cystic fibrosis epithelial cells by the $\alpha$-glucosidase inhibitor miglustat. FEBS Lett. 2006;580(8):2081-2086.

94. Lubamba B, Lebacq J, Lebecque P, et al. Airway delivery of lowdose miglustat normalizes nasal potential difference in F508del cystic fibrosis mice. Am J Respir Crit Care Med. 2009;179(11): 1022-1028.

95. Leonard A, Lebecque P, Dingemanse J, Leal T. A randomized placebocontrolled trial of miglustat in cystic fibrosis based on nasal potential difference. J Cyst Fibros. 2012;11(3):231-236.

96. Peak TC, Yafi FA, Sangkum P, Hellstrom WJG. Emerging drugs for the treatment of erectile dysfunction. Expert Opin Emerg Drugs. 2015;20(2):263-275.

97. Hambly N, Granton J. Riociguat for the treatment of pulmonary hypertension. Expert Rev Respir Med. 2015;9(6):679-695.

98. Leier G, Bangel-Ruland N, Sobczak K, Knieper Y, Weber WM. Sildenafil acts as potentiator and corrector of CFTR but might be not suitable for the treatment of CF lung disease. Cell Physiol Biochem. 2012;29(5-6):775-790.

99. Dormer RL, Harris CM, Clark Z, et al. Sildenafil (Viagra) corrects $\triangle$ F508-CFTR location in nasal epithelial cells from patients with cystic fibrosis. Thorax. 2005;60(1):55-59.

100. Dhooghe B, Noël S, Bouzin C, Behets-Wydemans G, Leal T. Correction of chloride transport and mislocalization of CFTR protein by vardenafil in the gastrointestinal tract of cystic fibrosis mice. PLoS One. 2013;8(10):e77314.

101. Lubamba B, Lecourt H, Lebacq J, et al. Preclinical evidence that sildenafil and vardenafil activate chloride transport in cystic fibrosis. Am J Respir Crit Care Med. 2008;177(5):506-515.

102. Taylor-Cousar JL, Wiley C, Felton LA, et al. Pharmacokinetics and tolerability of oral sildenafil in adults with cystic fibrosis lung disease. J Cyst Fibros. 2015;14(2):228-236.

103. Ghofrani HA, Galiè N, Grimminger F, et al. Riociguat for the treatment of pulmonary arterial hypertension. $N$ Engl J Med. 2013;369(4): $330-340$.

104. Mittendorf J, Weigand S, Alonso-Alija C, et al. Discovery of riociguat (BAY 63-2521): a potent, oral stimulator of soluble guanylate cyclase for the treatment of pulmonary hypertension. ChemMedChem. 2009;4(5):853-865.

105. Konstan MW, Schluchter MD, Xue W, Davis PB. Clinical use of ibuprofen is associated with slower FEV(1) decline in children with cystic fibrosis. Am J Respir Crit Care Med. 2007;176(11): 1084-1089.

106. Carlile GW, Robert R, Goepp J, et al. Ibuprofen rescues mutant cystic fibrosis transmembrane conductance regulator trafficking. J Cyst Fibros. 2015;14(1):16-25.

107. Gahl WA. Early oral cysteamine therapy for nephropathic cystinosis. Eur J Pediatr. 2003;162(1):S38-S41.

108. Luciani A, Villella VR, Esposito S, et al. Defective CFTR induces aggresome formation and lung inflammation in cystic fibrosis through ROS-mediated autophagy inhibition. Nat Cell Biol. 2010;12(9):863-875.

109. Abdulrahman BA, Khweek AA, Akhter A, et al. Autophagy stimulation by rapamycin suppresses lung inflammation and infection by Burkholderia cenocepacia in a model of cystic fibrosis. Autophagy. 2011;7(11):1359-1370.

110. Luciani A, Villella VR, Esposito S, et al. Targeting autophagy as a novel strategy for facilitating the therapeutic action of potentiators on $\Delta \mathrm{F} 508$ cystic fibrosis transmembrane conductance regulator. Autophagy. 2012;8(11):1657-1672.

111. Stefano DD, Villella VR, Esposito S, et al. Restoration of CFTR function in patients with cystic fibrosis carrying the F508del-CFTR mutation. Autophagy. 2014;10(11):2053-2074. 
112. Tosco A, De Gregorio F, Esposito S, et al. A novel treatment of cystic fibrosis acting on-target: cysteamine plus epigallocatechin gallate for the autophagy-dependent rescue of class II-mutated CFTR. Cell Death Differ. Epub 2016 Jul 22.

113. Sirtori CR. Aescin: pharmacology, pharmacokinetics and therapeutic profile. Pharmacol Res. 2001;44(3):183-193.

114. Mutyam V, Du M, Xue X, et al. Discovery of clinically approved agents that promote suppression of CFTR nonsense mutations. Am J Respir Crit Care Med. Epub 2016 Apr 22.

115. Ma T, Vetrivel L, Yang H, et al. High-affinity activators of cystic fibrosis transmembrane conductance regulator (CFTR) chloride conductance identified by high-throughput screening. J Biol Chem. 2002;277(40):37235-37241.

116. Pedemonte N, Lukacs GL, Du K, et al. Small-molecule correctors of defective $\triangle$ F508-CFTR cellular processing identified by highthroughput screening. J Clin Invest. 2005;115(9):2564-2571.

117. Van Goor F, Straley KS, Cao D, et al. Rescue of $\triangle F 508-C F T R$ trafficking and gating in human cystic fibrosis airway primary cultures by small molecules. Am J Physiol Lung Cell Mol Physiol. 2006;290(6): L1117-L1130.

118. Sermet-Gaudelus I, Renouil M, Fajac A, et al. In vitro prediction of stop-codon suppression by intravenous gentamicin in patients with cystic fibrosis: a pilot study. BMC Med. 2007;5:5-5.

119. Howard M, Frizzell RA, Bedwell DM. Aminoglycoside antibiotics restore CFTR function by overcoming premature stop mutations. Nat Med. 1996;2(4):467-469.

120. Bedwell DM, Kaenjak A, Benos DJ, et al. Suppression of a CFTR premature stop mutation in a bronchial epithelial cell line. Nat Med. 1997;3(11):1280-1284.

121. Wilschanski M, Yahav Y, Yaacov Y, et al. Gentamicin-induced correction of CFTR function in patients with cystic fibrosis and CFTR stop mutations. N Engl J Med. 2003;349(15):1433-1441.

122. Wilschanski M, Famini C, Blau H, et al. A pilot study of the effect of gentamicin on nasal potential difference measurements in cystic fibrosis patients carrying stop mutations. Am J Respir Crit Care Med. 2000;161(3):860-865.

123. Clancy JP, Bebök Z, Ruiz F, et al. Evidence that systemic gentamicin suppresses premature stop mutations in patients with cystic fibrosis Am J Respir Crit Care Med. 2001;163(7):1683-1692.

124. Clancy JP, Rowe SM, Bebok Z, et al. No detectable improvements in cystic fibrosis transmembrane conductance regulator by nasal aminoglycosides in patients with cystic fibrosis with stop mutations. Am J Respir Cell Mol Biol. 2007;37(1):57-66.

125. Nudelman I, Rebibo-Sabbah A, Cherniavsky M, et al. Development of novel aminoglycoside (NB54) with reduced toxicity and enhanced suppression of disease-causing premature stop mutations. J Med Chem. 2009;52(9):2836-2845.

126. Sabbavarapu NM, Shavit M, Degani Y, Smolkin B, Belakhov V, Baasov T. Design of novel aminoglycoside derivatives with enhanced suppression of diseases-causing nonsense mutations. ACS Med Chem Lett. 2016;7(4):418-423.

127. Xue X, Mutyam V, Tang L, et al. Synthetic aminoglycosides efficiently suppress cystic fibrosis transmembrane conductance regulator nonsense mutations and are enhanced by ivacaftor. Am J Respir Cell Mol Biol. 2014;50(4):805-816.

128. Rowe SM, Sloane P, Tang LP, et al. Suppression of CFTR premature termination codons and rescue of CFTR protein and function by the synthetic aminoglycoside NB54. J Mol Med (Berl). 2011;89(11): 1149-1161.

129. Du M, Jones JR, Lanier J, et al. Aminoglycoside suppression of a premature stop mutation in a $\mathrm{Cftr}^{-/-}$mouse carrying a human CFTRG542X transgene. J Mol Med (Berl). 2002;80(9):595-604.

130. Hamed S. Drug evaluation: PTC-124: a potential treatment of cystic fibrosis and Duchenne muscular dystrophy. IDrugs. 2006;9(11):783-789.

131. Kerem E, Hirawat S, Armoni S, et al. Effectiveness of PTC124 treatment of cystic fibrosis caused by nonsense mutations: a prospective phase II trial. Lancet. 2008;372(9640):719-727.
132. Sermet-Gaudelus I, De Boeck K, Casimir GJ, et al. Ataluren (PTC124) induces cystic fibrosis transmembrane conductance regulator protein expression and activity in children with nonsense mutation cystic fibrosis. Am J Respir Crit Care Med. 2010;182(10):1262-1272.

133. Kerem E, Konstan MW, De Boeck K, et al; Cystic Fibrosis Ataluren Study Group. Ataluren for the treatment of nonsense-mutation cystic fibrosis: a randomised, double-blind, placebo-controlled phase 3 trial. Lancet Respir Med. 2014;2(7):539-547.

134. Brown CR, Hong-Brown LQ, Biwersi J, Verkman AS, Welch WJ. Chemical chaperones correct the mutant phenotype of the $\Delta \mathrm{F} 508$ cystic fibrosis transmembrane conductance regulator protein. Cell Stress Chaperones. 1996;1(2):117-125.

135. Sato S, Ward CL, Krouse ME, Wine JJ, Kopito RR. Glycerol reverses the misfolding phenotype of the most common cystic fibrosis mutation. J Biol Chem. 1996;271(2):635-638.

136. Moyer BD, Loffing-Cueni D, Loffing J, Reynolds D, Stanton BA. Butyrate increases apical membrane CFTR but reduces chloride secretion in MDCK cells. Am J Physiol. 1999;277(2):F271-F276.

137. Rubenstein RC, Egan ME, Zeitlin PL. In vitro pharmacologic restoration of CFTR-mediated chloride transport with sodium 4-phenylbutyrate in cystic fibrosis epithelial cells containing delta F508-CFTR. $J$ Clin Invest. 1997;100(10):2457-2465.

138. Rubenstein RC, Zeitlin PL. Sodium 4-phenylbutyrate downregulates Hsc70: implications for intracellular trafficking of $\triangle$ F508-CFTR. Am J Physiol Cell Physiol. 2000;278(2):C259-C267.

139. Rubenstein R, Zeitlin P. A pilot clinical trial of oral sodium 4-phenylbutyrate (Buphenyl) in $\Delta \mathrm{F} 508$-homozygous cystic fibrosis patients. Am J Respir Crit Care Med. 1998;157(2):484-490.

140. Loo T, Bartlett M, Clarke D. Correctors promote folding of the CFTR in the endoplasmic reticulum. Biochem J. 2008;413(1):29-36.

141. Loo T, Bartlett M, Wang Y, Clarke D. The chemical chaperone CFcor325 repairs folding defects in the transmembrane domains of CFTRprocessing mutants. Biochem J. 2006;395(pt 3):537-542.

142. Hutt DM, Herman D, Rodrigues APC, et al. Reduced histone deacetylase 7 activity restores function to misfolded CFTR in cystic fibrosis. Nat Chem Biol. 2010;6(1):25-33.

143. Sampson H, Robert R, Liao J, et al. Identification of a NBD1-binding pharmacological chaperone that corrects the trafficking defect of F508del-CFTR. Chem Biol. 2011;18(2):231-242.

144. Ren HY, Grove DE, De La Rosa O, et al. VX-809 corrects folding defects in cystic fibrosis transmembrane conductance regulator protein through action on membrane-spanning domain 1. Mol Biol Cell. 2013;24(19):3016-3024.

145. Van Goor F, Hadida S, Grootenhuis PDJ, et al. Correction of the F508del-CFTR protein processing defect in vitro by the investigational drug VX-809. Proc Natl Acad Sci US A. 2011;108(46):18843-18848.

146. Clancy JP, Rowe SM, Accurso FJ, et al. Results of a phase IIa study of VX-809, an investigational CFTR corrector compound, in subjects with cystic fibrosis homozygous for the F508del-CFTR mutation. Thorax. 2012;67(1):12-18.

147. Boyle MP, Bell SC, Konstan MW, et al; VX09-809-102 Study Group. A CFTR corrector (lumacaftor) and a CFTR potentiator (ivacaftor) for treatment of patients with cystic fibrosis who have a phe508del CFTR mutation: a phase 2 randomised controlled trial. Lancet Respir Med. 2014;2(7):527-538.

148. Wainwright CE, Elborn JS, Ramsey BW, et al. Lumacaftor-ivacaftor in patients with cystic fibrosis homozygous for Phe508del CFTR. $N$ Engl J Med. 2015;373(3):220-231.

149. Jones AM, Barry PJ. Lumacaftor/ivacaftor for patients homozygous for Phe508del-CFTR: should we curb our enthusiasm? Thorax. 2015;70(7):615-616.

150. Orenstein DM, O’Sullivan BP, Quinton PM. Cystic fibrosis: breakthrough drugs at break-the-bank prices. Glob Adv Health Med. 2015;4(6):8-57.

151. Cholon DM, Quinney NL, Fulcher ML, et al. Potentiator ivacaftor abrogates pharmacological correction of $\triangle \mathrm{F} 508$ CFTR in cystic fibrosis. Sci Transl Med. 2014;6(246):246ra296. 
152. Veit G, Avramescu RG, Perdomo D, et al. Some gating potentiators, including VX-770, diminish $\triangle$ F508-CFTR functional expression. Sci Transl Med. 2014;6(246):246ra297.

153. Pilewski JM, Cooke J, Lekstrom-Himes J, Donaldson S. WS01.4 VX-661 in combination with ivacaftor in patients with cystic fibrosis and the F508del-CFTR mutation. J Cyst Fibros. 2015;14:S1.

154. Beumer W, Swildens J, Henig N, et al. WS01.2 QR-010, an RNA therapy, restores CFTR function using in vitro and in vivo models of delF508 CFTR. J Cyst Fibros. 2015;14:S1.

155. Henig N, Beumer W, Anthonijsz H, et al. QR-010, an RNA Therapy, Restores CFTR Function in the Saliva Secretion Assay. A37. It Won't be Long: Advances in Adult Cystic Fibrosis. New York, NY: American Thoracic Society; 2015:A1449-A1449.

156. Van Goor F, Hadida S, Grootenhuis PDJ, et al. Rescue of CF airway epithelial cell function in vitro by a CFTR potentiator, VX-770. Proc Natl Acad Sci U S A. 2009;106(44):18825-18830.

157. Accurso FJ, Rowe SM, Clancy JP, et al. Effect of VX-770 in persons with cystic fibrosis and the G551D-CFTR mutation. $N$ Engl J Med. 2010;363(21):1991-2003.

158. Davies J, Sheridan H, Bell N, et al. Assessment of clinical response to ivacaftor with lung clearance index in cystic fibrosis patients with a G551D-CFTR mutation and preserved spirometry: a randomised controlled trial. Lancet Respir Med. 2013;1(8):630-638.

159. Ramsey BW, Davies J, McElvaney NG, et al; VX08-770-102 Study Group. A CFTR potentiator in patients with cystic fibrosis and the G551D mutation. $N$ Engl J Med. 2011;365(18):1663-1672.

160. De Boeck K, Munck A, Walker S, et al. Efficacy and safety of ivacaftor in patients with cystic fibrosis and a non-G551D gating mutation. J Cyst Fibros. 2014;13(6):674-680.

161. Davies JC, Cunningham S, Harris WT, et al. Safety, pharmacokinetics, and pharmacodynamics of ivacaftor in patients aged 2-5 years with cystic fibrosis and a CFTR gating mutation (KIWI): an open-label, single-arm study. Lancet Respir Med. 2016;4(2):107-115.
162. Flume PA, Liou TG, Borowitz DS, et al; VX 08-770-104 Study Group. Ivacaftor in subjects with cystic fibrosis who are homozygous for the F508del-CFTR mutation. Chest. 2012;142(3):718-724.

163. Uttamsineh V, Pilja L, Grotbeck B, et al. WS13.6 CTP-656 tablet confirmed superiority of pharmacokinetic profile relative to Kalydeco ${ }^{\circledR}$ in phase I clinical studies. J Cyst Fibros. 2016; 15(S1):S22.

164. Shamsah K, Jose A, Laurie D, et al. QBW251 is a safe and efficacious CFTR potentiator for patients with cystic fibrosis. Am J Respir Crit Care Med. 2016;193:A7789.

165. Vanhoutte FP, Gouy M, Haazen W, et al. Safety, tolerability and pharmacokinetics of a novel CFTR potentiator GPLG1837 in healthy volunteers. Pediatr Pulmonol. 2015;50(S41):S289.

166. Marozkina NV, Yemen S, Borowitz M, et al. Hsp 70/Hsp 90 organizing protein as a nitrosylation target in cystic fibrosis therapy. Proc Natl Acad Sci US A. 2010;107(25):11393-11398.

167. Zaman K, Sawczak V, Zaidi A, et al. Augmentation of CFTR maturation by S-nitrosoglutathione reductase. Am J Physiol Lung Cell Mol Physiol. 2016;310(3):L263-L270.

168. Zaman K, Carraro S, Doherty J, et al. S-nitrosylating agents: a novel class of compounds that increase cystic fibrosis transmembrane conductance regulator expression and maturation in epithelial cells. $\mathrm{Mol}$ Pharmacol. 2006;70(4):1435-1442.

169. Taylor-Cousar J, Zemanick E, Solomon G. The pharmacokinetics of N91115, an inhibitor of S-nitrosoglutathione reductase in cystic fibrosis patients. Pediatr Pulmonol. 2015;50(S41):S285-S286.

170. Miller J, Drew L, Green O, et al. Amplifiers are a new class of CFTR modulators that increase the abundance of CFTR protein and combined with potentiators and correctors enhance chloride transport activity. Pediatr Pulmonol. 2015;50(S41):S265.

171. Dhooghe B, Haaf JB, Noel S, Leal T. Strategies in early clinical development for the treatment of basic defects of cystic fibrosis. Expert Opin Investig Drugs. 2016;25(4):423-436.
Clinical Pharmacology: Advances and Applications

\section{Publish your work in this journal}

Clinical Pharmacology: Advances and Applications is an international, peer-reviewed, open access journal publishing original research, reports, reviews and commentaries on all areas of drug experience in humans. The manuscript management system is completely online and includes a very quick and fair peer-review system, which is all easy to use.

\section{Dovepress}

Visit http://www.dovepress.com/testimonials.php to read real quotes from published authors. 